\title{
Phytochemical and Biological Studies on Bark Extract of Aporosa wallichii Hook.f.
}

\author{
Kazi Ruhullah Shahriar ${ }^{1,2}$, Siraj is Salekin ${ }^{1}$, Quazi Sufia Islam ${ }^{1}$, \\ Monira Ahsan ${ }^{1}$ and Choudhury M. Hasan ${ }^{1}$ \\ ${ }^{1}$ Phytochemical Research Laboratory, Department of Pharmaceutical Chemistry, Faculty of Pharmacy \\ University of Dhaka, Dhaka-1000, Bangladesh \\ ${ }^{2}$ Department of Pharmacy, State University of Bangladesh, 77 Satmasjid Road, Dhanmondi \\ Dhaka-1205, Bangladesh
}

(Received: August 14, 2020; Accepted: November 16, 2020; Published (web): December 10, 2020)

\begin{abstract}
The ethyl acetate extract of bark of Aporosa wallichii Hook.f. was extensively investigated for the chemical characterization of secondary metabolites and for biological activities. After repeated chromatographic separation and purification, two compounds were elucidated as a phenolic compound ferulic acid (1) and an uncommon triterpene glut-5(6)-en-3 $\beta$-ol (2) from the ethyl acetate extract of barks of $A$. wallichii by using high field NMR analyses. This is the first report of isolation of both compounds from this plant species. No significant antimicrobial activity was observed for any fraction after Kupchan partitioning of the extract. During the antioxidant activity assay, the ethyl acetate soluble fraction of A. wallichii demonstrated significant DPPH radical scavenging capacity with an $\mathrm{IC}_{50}$ value of $1.25 \mu \mathrm{g} / \mathrm{mL}$. The other fractions viz. petroleum ether, aqueous and chloroform soluble fractions exhibited moderate, mild, and weak activity respectively. The petroleum ether soluble fraction demonstrated maximum thrombolytic property $(51.33 \%)$ which was similar to that of standard streptokinase $(66.81 \%)$.
\end{abstract}

Keywords: Aporosa wallichii, ferulic acid, triterpene, thrombolytic, antioxidant.

\section{INTRODUCTION}

Aporosa wallichii Hook. f. is a flowering plant belonging to the family Phyllanthaceae. ${ }^{1}$ In Bangladesh, the plant is familiar as Kokra. This plant is distributed mainly in Assam, Bangladesh, Laos, Myanmar, Thailand. ${ }^{2,3}$ According to literature review, no phytochemical study was carried out previously on this plant. A recent study showed a significant level of antioxidant property, moderate level of thrombolytic and cytotoxic activity of $A$. wallichii. ${ }^{4,5}$ Furthermore, potential biological properties were shown by other Aporosa species. For example, there are antioxidant, anti-amylase and lipid-lowering properties of A. lindleyana. ${ }^{6}$ Antimicrobial, analgesic, and antidiuretic effects were also reported from this

Correspondence to: Choudhury M. Hasan

Email: cmhasan@gmail.com

Dhaka Univ. J. Pharma. Sci. 19(2): 139-143, 2020 (December)

DOI: https://doi.org/10.3329/dujps.v19i2.50629 plant. $^{7,8}$ A. aurea has different pharmacological properties, including antitrypanosomal activity and cytotoxicity. ${ }^{9}$ Since these Aporosa plants possess promising pharmacological potential, it can be hypothesized that $A$. wallichii also has such properties. Thus, the current study was designed to conduct phytochemical and biological investigations of Aporosa wallichii systematically.

\section{MATERIAL AND METHODS}

General experimental procedures. Vacuum liquid chromatography (VLC) was used following the prescribed method. ${ }^{10}$ The column of the apparatus was packed under vacuum with fine VLC grade silica (Kieselgel 60H) up to $6 \mathrm{~cm}$, followed by washing with $n$-hexane to ensure the compact packing of the column. Gel permeation chromatography technique was used mainly to separate chlorophyll from the rest of the compounds. Hence, Sephadex (LH-20) was 
used to pack the column. Sephadex was soaked in chloroform for $24 \mathrm{hrs}$ before packing the column. Column chromatography (CC) was performed on 70230 mesh silica gel 60 (Merck, Germany), while preparative thin layer chromatography (PTLC) $(20 \times$ $20 \mathrm{~cm})$ and thin layer chromatography (TLC) $(20 \times 5$ $\mathrm{cm}$ ) were performed on silica gel $60 \mathrm{PF}_{254}$ on 0.25 $\mathrm{mm}$ thick aluminium sheets (Merck, Germany). Fractions eluted VLC and CC upon rechromatography over TLC and PTLC, afforded compounds $\mathbf{1}$ and $\mathbf{2}$ in pure form. The ${ }^{1} \mathrm{H}$ NMR spectrum was recorded using a Bruker Avance (400 $\mathrm{MHz}$ ) instrument and referenced to the residual nondeuterated solvent signal.

Plant material. The bark of A. wallichii was collected in October 2018 from Sylhet district of Bangladesh. A voucher specimen of this collection of the plant was deposited at Bangladesh National Herbarium (BNH) (accession number DACB 46559). The bark was cleaned and cut into small fragments and then shade-dried for a week. The dried sample was then crushed into powder by a grinding machine.

Extraction and isolation. Powdered bark material $(1.26 \mathrm{~kg})$ was soaked in $3.0 \mathrm{~L}$ distilled ethyl acetate for eight days with occasional shaking and stirring. The filtrate was evaporated at $40^{\circ} \mathrm{C}$ and low pressure using Buchii Rotavapor rotary evaporator to get the crude extract of A. wallichii. The ethyl acetate crude extract was subjected to VLC for rapid fractionation using $n$-hexane, ethyl acetate and methanol in increasing order of polarities. GPC was used with different solvent systems (20\% $n$-hexane in chloroform, $10 \% n$-hexane in chloroform, $100 \%$ chloroform, $1 \% \mathrm{MeOH}$ in chloroform, $99 \% \mathrm{MeOH}$ in chloroform, $100 \% \mathrm{MeOH}$ ). Compound $\mathbf{1}$ was isolated from GPC Test Tube No. 1 of the VLC Fraction No. 12 (40\% EA in $n$-Hexane) of the ethyl acetate extract of barks of A. wallichii as white crystals. Whereas, the compound $\mathbf{2}$ was isolated as white crystals from GPC Fractions 14-16 of VLC Fraction No. 3 (2\% Ethyl Acetate (EA) in $n$-Hexane) of ethyl acetate extract of barks of $A$. wallichii.

Properties of isolated compounds. Ferulic Acid (1): White crystals; ${ }^{1} \mathrm{H}$ NMR (400 MHz, $\left.\mathrm{CDCl}_{3}\right): \delta$
$7.59(1 \mathrm{H}, \mathrm{d}, J=15.8 \mathrm{~Hz}, \mathrm{H}-3), 7.13(3 \mathrm{H}, \mathrm{dd}, J=8.2$, $1.7 \mathrm{~Hz}, \mathrm{H}-6$ ') 7.05 (3H, d, $J=1.7 \mathrm{~Hz}, \mathrm{H}-2$ '), 6.94 $(3 \mathrm{H}, \mathrm{d}, J=8.2 \mathrm{~Hz}, \mathrm{H}-5$ '), $6.48(1 \mathrm{H}, \mathrm{d}, J=15.8 \mathrm{~Hz}$, H-2), 5.86 (1H, s, 4'-OH), 3.95 (3H, s, 3'-O-Me).

Glut-5(6)-en-3 $\beta$-ol (2): White crystals; ${ }^{1} \mathrm{H}$ NMR $\left(400 \mathrm{MHz}, \mathrm{CDCl}_{3}\right): \delta 5.66(1 \mathrm{H}, \mathrm{d}, J=5.75, \mathrm{H}-6)$, 3.49 (1H, s, H-3), 1.19 (3H, s, H-29), 1.12 (3H, s, H26), 1.08 (3H, s, H-23), 1.04 (3H, s, H-30), 1.01 (3H, s, H-24), 0.98 (3H, s, H-25), 0.90 (3H, s, H-27), 0.88 $(3 \mathrm{H}, \mathrm{s}, \mathrm{H}-28)$.

Sample preparation for the determination of biological activities. For biological screening, about $5 \mathrm{~g}$ of crude extract of $A$. wallichii was subjected to solvent-solvent partitioning ${ }^{11}$ by petroleum ether, chloroform and ethyl acetate, respectively. After solvent-solvent partitioning, four solvent fractions were obtained namely petroleum ether soluble fraction (AWP), chloroform soluble fraction (AWC), ethyl acetate soluble fraction (AWE) and aqueous soluble fraction (AWA). These four fractions were used as test samples for biological studies.

Antioxidant activity. Antioxidant activity of the test sample was measured using 1,1-diphenyl-2picrylhydrazyl (DPPH) free radical scavenging assay. ${ }^{12}$ In this method, the ability of the test sample to react with DPPH radical in an alcoholic solution was calculated. After adding the test sample, the free radical solution was decolored, and the change in absorption was measured at $517 \mathrm{~nm}$ using a UV-Vis spectrophotometer. The reference standard butylated hydroxyl toluene (BHT) was used as a known hydrogen donor. Inhibition of DPPH radical scavenging was determined using the following equation:

$$
\mathrm{I} \%=\left(\mathrm{A}_{\text {control }}-\mathrm{A}_{\text {sample }}\right) / \mathrm{A}_{\text {control }} \times 100 \%
$$

Where, $\mathrm{A}_{\text {control }}$ was the absorbance of the DPPH solution without the test samples, and $\mathrm{A}_{\text {sample }}$ was the absorption of the sample with the test compounds. The concentration required for $50 \%$ inhibition $\left(\mathrm{IC}_{50}\right)$ was calculated on the basis of a percentage of inhibition vs concentration plot.

Thrombolytic activity. The thrombolytic activity of plant extracts was determined by standard 
$\operatorname{method}^{13}$ and the result was expressed as a percentage of blood clot lysis. Here, streptokinase (1500000 IU) and distilled water were used as the positive and negative control, respectively. Venous blood was taken from a healthy human volunteer and transferred to previously weighed sterile Eppendorf tubes. The tubes were incubated at $37^{\circ} \mathrm{C}$ for $45 \mathrm{~min}$. After incubation, the fluid was removed. Then the weights of the tube were measured again to observe the weight difference after clot disruption. $500 \mu \mathrm{l}$ (10 $\mathrm{mg} / \mathrm{ml}$ ) of the test sample was added to the Eppendorf tubes. $100 \mu \mathrm{l}$ of streptokinase and distilled water were added to each of the control tubes separately. All the tubes were incubated for $90 \mathrm{~min}$ at $37^{\circ} \mathrm{C}$, and clot lysis was observed. Then the left fluid was removed carefully. And once again, the tubes were weighed. The weight difference before and after the lysis of the clots was expressed as \% clot lysis. Following equation was used to determine $\%$ clot lysis:

$\%$ clot lysis $=($ weight of clot after lysis/weight of clot before lysis) $\times 100 \%$

Antimicrobial activity. Antimicrobial activity was assessed using disc diffusion method. ${ }^{14}$ Two Gram-positive and two Gram-negative bacteria were grown in separate Petri dishes with Muller-Hinton agar medium. Standard tetracycline, azithromycin, levofloxacin, and ciprofloxacin discs were used as positive control, while blank discs were used as the negative control. $20 \mu \mathrm{l}$ solution from $20 \mathrm{mg} / \mathrm{ml}$ of the each Kupchan fraction was added to the blank disc to achieve the concentration of $400 \mu \mathrm{g} / \mathrm{disc}$. The sample discs and standard antibiotic discs were gently placed on the previously marked spots in the pre-inoculated agar plates with the test bacteria. Then the plates were incubated at $37^{\circ} \mathrm{C}$ for $24 \mathrm{hrs}$. The antimicrobial potency of the sample agents was calculated by their action to prevent the growth of the microorganisms surrounding the discs that gave a transparent zone of inhibition. After incubation, the antimicrobial activity of the sample partitionates was evaluated by measuring the diameter of the zones of inhibition (in $\mathrm{mm}$ ) using a transparent scale.

\section{RESULTS AND DISCUSSION}

Two compounds (1 and 2) were isolated and purified using repeated chromatographic procedures from the ethyl acetate extract of the stem bark of $A$. wallichii. The structures of those isolated compounds were elucidated by comparing their published ${ }^{1} \mathrm{H}$ NMR data available in literature.

The ${ }^{1} \mathrm{H}$ NMR spectrum of compound 1 revealed the presence of doublets at $\delta 7.05(J=1.7 \mathrm{~Hz})$ and at $\delta 6.94(J=8.2 \mathrm{~Hz})$, and a double-doublet at $\delta 7.13(J$ $=8.2 \& 1.7 \mathrm{~Hz})$ which attributed an ortho and parasubstituted aromatic ring. The presence of a singlet signal at $\delta 3.95$ is characteristic for three protons of a methoxy group that is located at ortho position to the phenolic $\mathrm{OH}$ group. Two doublets at $\delta 7.59$ and 6.48 indicated olefinic protons located at $\alpha$ and $\beta$ positions, respectively to a carbonyl group. The $J$ value 15.8 is characteristic for trans coupling. The above spectral data are in very close agreement to those found in published data for ferulic acid. ${ }^{15}$ This is the first-time report of ferulic acid from $A$. wallichii.

The ${ }^{1} \mathrm{H}$ NMR (400 MHz, CDCl3) of compound 2 showed a doublet at $\delta 5.66$ which is characteristic for an olefinic proton and a signal at $\delta 3.49$ indicating the presence of an oxymethine proton assignable to $\mathrm{H}-6$ and $\mathrm{H}-3$, respectively. The signals attributing for eight methyl singlets were observed at $\delta 1.19,1.12$, $1.08,1.04,1.01,0.98,0.90$ and 0.88 . Based on these spectral features, compound 2 was characterized as an uncommon triterpene named glut-5(6)-en-3 $\beta$-ol. The identity of compound $\mathbf{2}$ was further confirmed by comparison of its ${ }^{1} \mathrm{H}$ NMR data with previously published data. ${ }^{16}$ This is the first report of glut-5(6)-

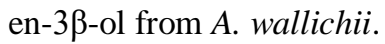

Antioxidant activity. BHT was used as the positive control for which the $\mathrm{IC}_{50}$ was found to be $5.85 \mu \mathrm{g} / \mathrm{ml}$. Among Kupchan fractions, ethyl acetate fraction showed the highest free radical scavenging activity $\left(\mathrm{IC}_{50} 1.25 \mu \mathrm{g} / \mathrm{ml}\right)$. Other fractions also showed mild to moderate antioxidant activity (Table $1)$. 
<smiles>COc1cc(/C=C/C(=O)O)ccc1O</smiles>

Compound (1): Ferulic acid

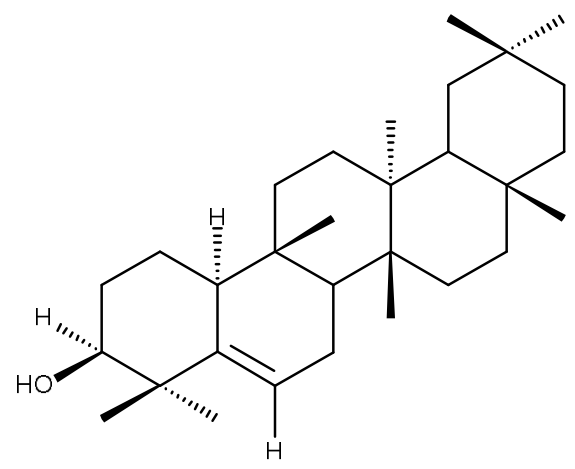

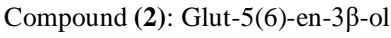

Figure 1. Structures of the compounds obtained from $A$. wallichii.

Table 1. Free radical scavenging activity of different fractions of $A$. wallichii.

\begin{tabular}{lc}
\hline Sample & $\mathrm{IC}_{50}$ value $(\mu \mathrm{g} / \mathrm{ml})$ \\
\hline BHT & 5.85 \\
AWP & 12.96 \\
AWC & 24.23 \\
AWE & 1.25 \\
AWA & 16.88 \\
\hline
\end{tabular}

BHT: Tert-butyl-1-hydroxytoluene, AWP: Petroleum ether soluble fraction of A. wallichii, AWC: Chloroform soluble fraction of $A$. wallichii, AWE: Ethyl acetate soluble fraction of A. wallichii, AWA: Aqueous fraction of A. wallichii.

Table 2. Thrombolytic activity of different soluble fractions of A. wallichii.

\begin{tabular}{lc}
\hline Sample & \% of clot lysis \\
\hline Distilled water & 1.52 \\
Streptokinase & 66.81 \\
AWP & 51.33 \\
AWC & 18.00 \\
AWE & 10.53 \\
AWA & 21.02 \\
\hline
\end{tabular}

Thrombolytic activity. Among all fractions, the petroleum ether fraction showed the highest thrombolytic activity (51.33\%), whereas standard streptokinase showed $66.81 \%$ clot lysis at $37^{\circ} \mathrm{C}$ (Table 2).

Antimicrobial activity. Antimicrobial activity of different fractions of A. wallichii was evaluated against two Gram-positive (Bacillus subtilis, Staphylococcus aureus) and five Gram-negative (Escherichia coli, Salmonella typhi, Shigella flexneri, Pseudomonas aeruginosa, Vibrio sp.) bacterial species. Tetracycline, azithromycin, levofloxacin, and ciprofloxacin were used as positive controls while distilled water was used as the negative control. Kupchan fractions of $A$. wallichii did not show any antimicrobial activity at $400 \mu \mathrm{g} / \mathrm{disc}$ dose.

\section{CONCLUSION}

Repeated chromatographic separation and purification of the ethyl acetate crude extract of the bark of Aporosa wallichii afforded two pure compounds ferulic acid (1) and glut-5(6)-en-3ß-ol (2). Both the compounds have been reported for the first time from this plant.

Test materials of $A$. wallichii were involved in few biological screenings. Of which the antioxidant and thrombolytic activity of the plant extractives were significant.

Therefore, the plant materials can be further studied considering the potential bioactivity to assess their unexplored effectiveness and rationalize their applications as conventional medicines.

\section{REFERENCES}

1. Bingtao, L. and Gilbert, M.G. 2008. Aporosa Blume. Fl. China 11, 215-216.

2. Hossain, M.A., Hossain, M.K., Alam, M.S., Uddin, M.M. 2015. Composition and diversity of tree species in Kamalachari natural forest of Chittagong South forest division, Bangladesh. J. For. Environ. Sci. 31, 192-201.

3. Govaerts, R. 2017. In: World checklist of selected plant families. (Roskov Y., Abucay L., Orrell T., Nicolson D., Bailly N., Kirk P.M., Bourgoin T., DeWalt R.E., Decock W., Wever A., Nieukerken E. van, Zarucchi J., Penev L., Eds.), Species 2000 ITIS Cat. Life, 2018 Annu. Checkl. 
4. Islam, M.N. 2017. In vitro biological screening of methanol extract of Aporosa wallichii (Euphorbiaceae) Leaves. Undergraduate Project, BRAC University, Bangladesh. p. 44.

5. Sharmin, S., Kabir, M.T., Islam, M.N., Jamiruddin, M.R., Rahman, I., Rahman, A. and Hossain, M. 2018. Evaluation of antioxidant, thrombolytic and cytotoxic potentials of methanolic extract of Aporosa wallichii Hook. f. leaves: an unexplored phytomedicine. J. Appl. Pharm. Sci. 8, 51-56.

6. Kathirgamanathar, S., Abeysekera, W.P.K.M., Weerasinghe, D.M.K.P., Ranasinghe, P. and Binduhewa, A.M.C.U. 2018. Antioxidant, anti-amylase and lipid lowering potential of leaves of Aporosa lindleyana Baill. (Kebella). Sri Lankan J. Biol. 3, 880-892.

7. Srikrishna, L.P., Vagdevi, H.M., Basavaraja, B.M. and Vaidya, V.P. 2008. Evaluation of antimicrobial and analgesic activities of Aporosa lindleyana (Euphorbiaceae) bark extract. Int. J. Green Pharm. 2, 155-157.

8. Ganegamage, S.K., Abeytunga, T.U. and Ratnasooriya, W.D. 2014. Antidiuretic activity of the methanol extract of Aporosa lindleyana wight (Euphorbiaceae) baillon in rats. Trop. J. Pharm. Res. 13, 1099-1105.

9. Mohmod, A.L., Krishnasamy, G. and Adenan, M.I. 2015. Malaysian plants with potential in vitro trypanocidal activity. Ann. Phytomedicine 4, 6-16.

10. Pelletier, S.W., Chokshi, H.P. and Desai, H.K. 1986. Separation of diterpenoid alkaloid mixtures using vacuum liquid chromatography. J. Nat. Prod. 49, 892-900. 